\title{
Beta3-Adrenergic Receptor ( $\beta 3-A R$ ) Modulation Prior to and / or at the end of Sustained Ischaemia and / or Early Reperfusion May Prove to be a Valuable Cardioprotective Strategy
}

Ruduwaan Salie ( $\square$ ruduwaan.salie@mrc.ac.za)

South African Medical Research Council https://orcid.org/0000-0001-9396-4025

\section{Erna Marais}

Stellenbosch University

Amanda Lochner

Stellenbosch University

\section{Short Report}

Keywords: myocardial ischaemia, reperfusion injury, cardioprotection, $\beta 3-$ AR modulation

Posted Date: October 18th, 2021

DOl: https://doi.org/10.21203/rs.3.rs-982400/v1

License: (c) (1) This work is licensed under a Creative Commons Attribution 4.0 International License.

Read Full License 
Beta3-Adrenergic Receptor ( $\beta 3-\mathrm{AR})$ modulation prior to and / or at the end of sustained ischaemia and / or early reperfusion may prove to be a valuable cardioprotective strategy

Ruduwaan Salie $^{(1)}$, Erna Marais ${ }^{(2)}$, Amanda Lochner ${ }^{(2)}$

(1) South African Medical Research Council, Biomedical Research and Innovation Platform, Cape Town Western Cape, South Africa

(2) Stellenbosch University, Faculty of Medicine and Health Sciences, Cape Town, Western Cape, South Africa

\section{Corresponding author:}

Dr. Ruduwaan Salie

South African Medical Research Council, Biomedical Research and Innovation Platform, Cape Town Western Cape, South Africa

e-mail: Ruduwaan.salie@mrc.ac.za

Tel: +27 219380338

Cell: +27836507069

\section{Co-authors:}

Dr. Erna Marais

Division of Medical Physiology, Faculty of Medicine and Health Sciences, University of

Stellenbosch, Tygerberg, PO Box 19063, Cape Town, South Africa

e-mail: et4@sun.ac.za

Tel: +27219389391

Cell: +27828554725

Professor Amanda Lochner

Division of Medical Physiology, Faculty of Medicine and Health Sciences, University of Stellenbosch, Tygerberg, PO Box 19063, Cape Town, South Africa

e-mail: alo@sun.ac.za

Key words: myocardial ischaemia, reperfusion injury, cardioprotection, $\beta 3$-AR modulation

Subject Area: Beta3-Adrenergic Receptor ( $\beta 3-\mathrm{AR})$ mediated Cardioprotection

Total word count: 1197 


\begin{abstract}
$\beta 3$-AR activation contributes partly or may be solely responsible for ensuing cardiac damage in myocardial ischaemia or heart failure. This would largely depend on disease stage, severity, experimental model as well as drug specificities which should be considered when investigating $\beta 3$-AR pharmacology for potential therapeutic applications. These conceptions largely contribute to the discrepancies of the subsequent role of $\beta 3$-AR activation in the cardiovascular disease process. The $\beta 3$-AR delivers a sustained intracellular signal because of its resistance to short term agonist promoted desensitization, making this receptor an ideal target for therapeutic intervention and in this manner protecting the heart from catecholamine overstimulation. The current communication highlights the importance of the cumulative effect of BRL (PerT) treatment, at the end stage of ischaemia as well as BRL (PostT) treatment, at the onset of reperfusion. This undoubtedly illustrate the significance of the end stage of ischaemia as well as the onset of reperfusion in the concept of ischaemia- reperfusion damage and the importance of the application of cardioprotective interventions at these time periods. Subsequently, if cardioprotective regimens are initiated during the late phase of ischaemia and continued into early reperfusion, it is likely that they will enhance protection, especially with longer durations of ischaemia.
\end{abstract}

The historical viewpoint of ischaemia-reperfusion (IR) damage highlighted in the review of Turer and Hill, 2010 [1] emphasize the crucial observation of Jennings and colleagues, 1960 [2] that reperfusion following ischaemia was associated with myocardial injury. In this milieu, reperfusion is additive to that component of cell death due to the ischaemic event itself; on the other hand, reperfusion is an essential element of cardioprotection [3]. Previous studies have investigated the capability of cardioprotective interventions or drugs administered at the onset of reperfusion to reduce infarct size $[4,5]$ and it is established that transient $\beta$-adrenergic activation with isoproterenol, formoterol or dobutamine before acute myocardial ischaemia (AMI), elicits cardioprotection against subsequent ischaemia [6, 7]. In this context, the emphasis was largely on the $\beta 1$ - and $\beta 2$-adrenergic receptors but of late the $\beta 3$-AR has been explored as a potential target in the treatment of acute myocardial infarction (AIM) and / or heart disease, which highlights a possible cardioprotective role of $\beta 3$-AR activation in reperfusion injury.

The $\beta 3$-AR is identified as the third isoform of human $\beta$-AR [8] and is recognized for its role in smooth muscle cell relaxation in the bladder, gastrointestinal and urinary tract $[9,10]$. It is documented to be involved in cardiovascular control, due to its expression in vascular endothelial cells [11, 12] atrial and ventricular cardiac myocytes [13]. Normally in myocardial tissue, the $\beta 1(80 \%)$ and $\beta 2$-AR (17\%) are more abundantly expressed compared to the low levels of $\beta 3-\mathrm{AR}(3 \%)$ [14]. However, the percentage of $\beta 3-\mathrm{AR}$ is increased in myocardial ischaemia or heart failure [13], activates the conventional eNOS/NO/cGMP pathway which decreases residual $\beta 1 / \beta 2$-AR effects on contractility and subsequently protecting the heart from $\beta 1$-AR overstimulation [15]. The $\beta 3$-AR lacks serine and threonine residues sequences on the third intracellular loop and $\mathrm{C}$-terminal tail targeted by $\mathrm{G}$ protein-coupled receptor kinases (GPCR kinases) or cAMP-dependent protein kinase (PKA) phosphorylation making this receptor resistant to agonistinduced desensitization [16]. It is important to note whether subsequent activation of the $\beta 3$-AR contribute partly or solely responsible for the ensuing cardiac damage. This would largely depend on disease stage, severity, experimental 
model as well as drug specificities which should be considered when investigating $\beta 3$-AR pharmacology for potential therapeutic applications. These conceptions may largely contribute to the inconsistencies of the subsequent role of $\beta 3$ AR activation in the cardiovascular disease process.

This was evidently illustrated when the $\beta 3$-AR agonist (BRL37344, $1 \mu \mathrm{M}$ ) was administered before ischaemia as a pre- treatment (PreT) or at the end stage of ischaemia, labelled as per-treatment (PerT) or at the onset of reperfusion as a post- treatment (PostT), all of which reduced infarct size in isolated rat hearts [17]. However, this cardioprotective effect could not be reproduced with mirabegron, an $\beta 3$-AR agonist with high specificity for the human $\beta 3$-AR in a swine model of ischaemia-reperfusion in-vivo; when applied in the same context near the end stage of ischaemia before reperfusion, did not improve LV functional recovery or reduce infarct size after 7 or 45 days post-IR [18]. In the in-vivo swine heart failure model, continuously high systemic catecholamine levels may result in unremitting $\beta 3$ AR activation, which will ultimately culminate in dilated cardiomyopathy, remodeling and fibrosis and perhaps transient $\beta 3$-AR inhibition should have been considered at the onset of reperfusion. This was clearly illustrated when BRL (PerT) was followed by $\beta 3$-AR inhibition with SR59230A (SR) at the onset of reperfusion in the BRL (PerT)+SR (PostT) treatment group, which was associated with reduce infarct size, significant extra cellular regulated kinase (ERKp44/p42), phosphatidylinositol 3-kinase-protein kinase B (PKB/Akt), endothelial nitric oxide synthase (eNOS) as well as GSK-3 $\beta$ phosphorylation [17]. Contrary to the in-vivo swine heart failure model, the isolated working rat heat model is a well-regulated model of myocardial ischaemia-reperfusion with adequate nerve supply, independent of overall extraneuronal catecholamine release or central sympathetic drive [19].

However, increased catecholamine levels in the event of ischaemia [20], results in the up-regulation of the $\beta 3-\mathrm{AR}$ population and a synchronized $\beta 1$ - and $\beta 2$-ARs down-regulation. In this setting the $\beta 3$-AR delivers a sustained intracellular signal [21] because of its resistance to short term agonist promoted desensitization [16], making this receptor an ideal target for therapeutic intervention and in this manner protecting the heart from catecholamine overstimulation [22]. Subsequently, $\beta 3$-AR modulation prior to and / or at the end of sustained ischaemia and / or early reperfusion may prove to be a valuable cardioprotective strategy [17]. Even though cardioprotection was achieved in this context with transient $\beta 3$-AR activation, the correlation between infarct size reduction and activation of cardioprotective signaling pathways were not always comprehensible [17]. For example, the cardioprotective effect of $\beta 3$-AR stimulation with selective $\beta 3$-AR agonist BRL37344, applied as BRL (PreT), BRL (PerT) or at the end stage of ischaemia as BRL (PostT), were achieved without significant activation of eNOS, ERKp44/p42 or GSK-3 $\beta$ phosphorylation but significantly increased cGMP levels and PKB/Akt activation. This may be due to partial activation of the Reperfusion injury salvage kinase (RISK) pathway, namely PKB/Akt and not ERKp44/p42, both of which features prominently in the cardioprotection of ischemic preconditioning [23]. In this instance, it can also be speculated that the absence of eNOS activation with BRL (PreT) or BRL (PerT) may be due to the lack of significant ERKp44/p42 activation, since similar findings shows the involvement of ERKp44/p42 in the regulation of eNOS at Ser602 in bovine aortic endothelial cells (BAECs) [24] as well as the role of ERKp44/p42 and p38 signalling pathways in eNOS activation [25]. 
The possible connection between elevated cGMP levels and PKB/Akt activation found with the cardioprotection of BRL (PreT) or BRL (PerT) [17], may be consistent with an eNOS-dependent pathway where cGMP levels, a downstream effector of $\mathrm{NO}$ are elevated in smooth muscle cells in which constitutively-active Akt (myr-Akt) is expressed [26]. The involvement of atrial natriuretic peptide (ANP) should also be considered, since it was found that the application of ANP at reperfusion protected against I/R injury [27] and exerted antiapoptotic effects in rat cardiomyocytes through cGMP-PKG by inducing PI3K/Akt signaling. Similarly, it can be ventured to say that the cardioprotection achieved with BRL (PreT) or BRL (PerT) may have had an element of ANP activation, subsequent $\mathrm{PKB} /$ Akt activation and accompanying increased cGMP levels. However, this idea and the way cardioprotection was achieved in the absence of GSK-3 $\beta$ phosphorylation remain to be explored.

On the other hand, $\beta 3$-AR stimulation at the beginning of reperfusion, BRL (PostT), significantly reduced infarct size, marginally increased eNOS activation, significantly increased cGMP levels, PKB/Akt as well as ERKp44/p42 phosphorylation. However, combining BRL (PostT) with BRL (PerT) in the experimental group BRL (PerT+PostT), followed the conventional $\beta 3-\mathrm{AR} / \mathrm{NNOS} / \mathrm{NO} / \mathrm{cGMP}$ signaling cascade and produced a synergistic effect in terms of cardioprotection, significant PKB/Akt, ERKp44/p42 as well as GSK-3 $\beta$ phosphorylation [17]. The addition of BRL (PostT) at the onset of reperfusion to BRL (PerT) at the end stage of ischaemia, undoubtedly illustrate the significance of the end stage of ischaemia as well as the onset of reperfusion in the concept of ischaemia-reperfusion damage and importance of the application of cardioprotective interventions at these time periods. Subsequently, if cardioprotective regimens are initiated during the late phase of ischaemia and continued into early reperfusion, it is likely that they will enhance protection, especially with longer durations of ischaemia.

\section{Funding Details}

The work of the previous publication; Cardioprotective effects of Beta3-Adrenergic Receptor ( $\beta 3$-AR) pre-, per- and post-treatment in ischaemia-reperfusion. Cardiovascular Drugs and Therapy. 2019; 33(2):163-177 (DOI: 10.1007/s10557-019-06861-5), on which the current short communication is based; was supported by the Biomedical Research and Innovation Platform, South African Medical Research Council and the Faculty of Medicine and Health Sciences, Division of Medical Physiology, University of Stellenbosch.

\section{Conflict of interest to disclosure}

All co-authors have read and approved the manuscript for submission to the journal of Cardiovascular Drugs and Therapy. We the authors of this manuscript, declare that we have no conflict of interest.

Availability of data and material: Not applicable

Code availability: Not applicable

\section{Author contributions}

The first draft of the manuscript was written by Dr Ruduwaan Salie and all authors commented on previous versions of the manuscript. All authors read and approved the final manuscript. 


\section{Experimental Animal Ethics}

The handling of laboratory animals (male Wistar rats) used in the previous study was in accordance to ethical guidelines as set out by the University of Stellenbosch, Faculty of Medicine and Health Sciences Ethics Committee and the South African National Standard for Care and Use of Animals for Scientific Purpose (SANS 588 10386: 2008).

\section{References}

1. Turer AT \& Hill JA. Pathogenesis of Myocardial Ischemia-Reperfusion Injury and Rationale for Therapy. 685 Am J Cardiol. 2010; 106 (3): 360-368. 686687.

2. Jennings RB, Sommers HM, Smyth GA, Flack HA, Linn H. Myocardial necrosis induced by temporary 688 occlusion of a coronary artery in the dog. Arch Pathol. 1960; 70: 68-78. 689690.

3. Park JL \& Lucchesi BR. Mechanisms of Myocardial Reperfusion Injury. Ann Thorac Surg. 1999; 68: 1905- 69112.

4. Murphy E \& Steenbergen C. Mechanisms Underlying Acute Protection from Cardiac IschemiaReperfusion 598 Injury. Physiological Reviews. 2008; 88(2): 581-609.

5. Bullard AJ, Govewalla P \& Yellon DM. Erythropoietin Protects the Myocardium Against Reperfusion Injury 669 in Vitro and in Vivo. Basic Res Cardiol. 2005; 100(5): 397-403.

6. Asimakis GK and Conti VR. Preconditioning with dobutamine in the isolated rat heart. Life Sciences. 1995; 57(2): 177-187.

7. Salie R, Moolman JA, Lochner A. The Role of $\beta$-adrenergic Receptors in the Cardioprotective Effects of Beta-Preconditioning ( $\beta P C)$. Cardiovasc Drugs Ther. 2011; 25(1): 31-46

8. Emorine LJ, Marullo S, Briend-Sutren MM, Patey G, Tate K, Delavier-Klutchko C, Strosberg AD. Molecular characterization of the human beta 3-adrenergic receptor. Science. 1989; 245: 1118-1121.

9. Otsuka A, Shinbo H, Matsumoto R, Kurita Y, Ozono S. Expression and functional role of $\beta$-adrenoceptors in the human urinary bladder urothelium. Naunyn Schmiedebergs Arch. Pharmacol. 2008; 377: 473-481.

10. Schepelmann A, Strosberg G, Wakefield DP. Localization of the $\beta$ (beta)3-adrenoceptor in the human gastrointestinal tract: an immunohistochemical study. Alimentary Pharmacology \& Therapeutics. 2001; (12): 519-525.

11. Trochu JN, Leblais V, Rautureau Y, Bévérelli F, Le Marec H, Berdeaux A. Gauthier, C. Beta 3adrenoceptor stimulation induces vasorelaxation mediated essentially by endothelium-derived nitric oxide in rat thoracic aorta. Br. J. Pharmacol. 1999; 128: 69-76.

12. Dessy C, Moniotte S, Ghisdal P, Havaux X, Noirhomme P, Balligand JL. Endothelial beta3-adrenoceptors mediate vasorelaxation of human coronary microarteries through nitric oxide and endothelium-dependent hyperpolarization. Circulation. 2004; 110: 948-954.

13. Gauthier C, Tavernier G, Charpentier F, Langin D, Le Marec, H. Functional beta3-adrenoceptor in the human heart. J. Clin. Investig. 1996; 98: 556-562.

14. Bristow MR, Ginsburg R, Umans V, Fowler M, Minobe W, Rasmussen R, Zera P, Menlove R, Shah P, Jamieson S. Beta 1- and beta 2-adrenergic-receptor subpopulations in nonfailing and failing human 
ventricular myocardium: Coupling of both receptor subtypes to muscle contraction and selective beta 1receptor down-regulation in heart failure. Circ. Res. 1986; 59: 297-309.

15. Moens AL, Yang R, Watts VL and Barouch LA. Beta 3-adrenoreceptor Regulation of Nitric Oxide in the Cardiovascular System. J Mol Cell Cardiol. 2010; 48(6): 1088-1095.

16. Liggett SB, Freedman NJ, Schwinn DA \& Lefkowitz RJ. Structural Basis for Receptor Subtype-Specific 618 Regulation Revealed by a Chimeric Beta 3/ beta 2-Adrenergic Receptor. PNAS. 1993; 90(8): 36653669.

17. Salie R, Alsalhin AKH, Marais E, Lochner A. Cardioprotective Effects of Beta3-Adrenergic Receptor ( $\beta 3$ AR) Pre-, Per-, and Post-treatment in Ischemia-Reperfusion. Cardiovasc. Drugs Ther. 2019; 33: 163-177.

18. Rossello X, Piñero A, Fernández-Jiménez R, Sánchez-González J, Pizarro G, Galán-Arriola C, LoboGonzalez M, Vilchez JP, García-Prieto J, García-Ruiz JM, et al. Mirabegron, a Clinically Approved $\beta 3$ Adrenergic Receptor Agonist, Does Not Reduce Infarct Size in a Swine Model of Reperfused Myocardial Infarction. J. Cardiovasc. Transl. Res. 2018; 11: 310-318.

19. Schomig A, Dart AM, Dietz R, Mayer E and Kiibler W. Release of Endogenous Catecholamines in the Ischemic Myocardium of the Rat. Circ Res. 1984; 55: 689-701.

20. Perrone MG and Scilimati A. Beta 3-Adrenoceptor Agonists and (Antagonists) Inverse Agonists: History, 662 Perspective, Constitutive Activity and Stereospecific Binding. Methods Enzymol. 2010, 484 (11

21. Granneman GJ. Why do adipocytes make the $\beta 3$ adrenergic receptor ? Cell Signal. 1995, 7(1): 9-15.

22. Niu X, Watts VL, Cingolani OH, Sivakumaran V et al. Cardioprotective effect of beta-3 adrenergic receptor agonism: role of neuronal nitric oxide synthase. J Am Coll Cardiol. 2012; 59(22): 1979-87.

23. Hausenloy DJ, Tsang A \& Yellon DM. The Reperfusion Injury Salvage Kinase Pathway: A Common 672 Target for both Ischemic Preconditioning and Postconditioning. TCM. 2005; 15(2): 69-75.

24. Salerno JC, Ghosh DK, Razdan R, Helms KA, Brown CC, McMurry JL, Rye EA and Chrestensen CA. Endothelial nitric oxide synthase is regulated by ERK phosphorylation at Ser602. Biosci. Rep. 2014; 34.

25. Bernier SG, Haldar S and Michel T. Bradykinin-regulated interactions of the mitogen-activated protein kinase pathway with the endothelial nitric-oxide synthase. J. Biol. Chem. 2000; 275: 30707-30715.

26. Luo L, Fujio Y, Kureishi Y, Rudic RD, Daumerie G, Fulton D, Sessa WC, Walsh K. Acute modulation of endothelial Akt/PKB activity alters nitric oxide-dependent vasomotor activity in vivo. J Clin Invest. 2000; 106(4): 493-499.

27. Kato T, Muraski J, Chen Y, et al. Atrial natriuretic peptide promotes cardiomyocyte survival by cGMPdependent nuclear accumulation of zyxin and Akt. J Clin Invest 2005; 115:2716-30. 